\title{
ENTRE-TEXTOS: UM OLHAR SOBRE AS POLÍTICAS PÚBLICAS DE FORMAÇÃO DE LEITORES E SUAS EXPRESSÕES NO IFRO - CAMPUS PORTO VELHO CALAMA
}

\author{
Ruth Ferreira Bezerra ${ }^{1}$ \\ Xênia de Castro Barbosa ${ }^{2}$
}

Recebido em: janeiro/2020

Publicado em: abril/2020

\section{RESUMO:}

Este texto propõe reflexão sobre as políticas públicas de formação de leitores promovidas pelo Estado brasileiro no âmbito do Ministério da Educação e as formas de replicação dessas políticas nacionais no Campus Porto Velho Calama e busca, ainda, avaliar as experiências e dificuldades de leitura apresentadas pelos estudantes do curso de Eletrotécnica Integrado ao Ensino Médio da referida unidade educacional. Pautou-se em abordagem qualitativa, inserindo-se no campo da pesquisa educacional. Envolveu procedimentos da pesquisa de campo e da pesquisa documental e seu recorte empírico foi o Campus Porto Velho Calama do Instituto Federal de Educação, Ciência e Tecnologia de Rondônia. Quanto à natureza configura-se como Pesquisa Básica e quanto aos objetivos, como Pesquisa Explicativa. No que diz respeito aos procedimentos utilizados, caracteriza-se como Pesquisa Educacional (GIL, 2008; FAZENDA, 2000). O estudo contribui com dados atualizados sobre os desafios da formação de leitores no IFRO.

Palavras-chave: leitura; leitor; educação.

\footnotetext{
${ }^{1}$ Especialista em Metodologia da Educação Profissional e Tecnológica pelo IFRO. Professora de Língua Portuguesa do Colégio Paul Aenis. E-mail: rwthbezerra@ hotmail.com

${ }^{2}$ Doutora em Geografia pela UFPR. Docente do Programa de Mestrado em Rede Nacional em Educação Profissional e Tecnológica do IFRO - Campus Porto Velho Calama: xenia.castro@ifro.edu.br
} 


\title{
INTER-TEXTS: A LOOK AT THE PUBLIC POLICIES OF READER EDUCATION AND THEIR EXPRESSIONS AT IFRO - CAMPUS PORTO VELHO CALAMA
}

\begin{abstract}
:
This text proposes a reflection on the public policies for the formation of readers promoted by the Brazilian State within the Ministry of Education and the ways of replicating these national policies in the Porto Velho Calama Campus. It also seeks to evaluate the reading experiences and difficulties presented by the students. of the Electrotechnical Integrated to High School course of the referred educational unit. It was based on a qualitative approach, inserting itself in the field of educational research. It involved field research and documentary research procedures and its empirical approach was the Porto Velho Calama Campus of the Federal Institute of Education, Science and Technology of Rondônia. The nature is configured as Basic Research and the objectives as Explanatory Research. With regard to the procedures used, it is characterized as Educational Research (GIL, 2008; Fazenda, 2000). The study provides up-to-date data on the challenges of IFRO reader education.
\end{abstract}

Keywords: Reading; Reader; Education.

\section{INTRODUÇÃO}

A capacidade de leitura textual é uma demanda da Educação Profissional e Tecnológica, na medida em que o aprendiz precisa tanto interpretar e construir informações necessárias à sua formação profissional, quanto desenvolver o senso crítico em relação aos problemas sociais - atitude esperada de cidadãos.

Em razão de processos de alfabetização deficitários, a capacidade de êxito na vida acadêmica e a capacidade de exercício da cidadania podem ser comprometidas, levando ao analfabetismo funcional e restringindo o desenvolvimento profissional e o êxito acadêmico, favorecendo, portanto, a reprodução de mazelas sociais. A dificuldade 
na leitura implica, dessa forma, na dificuldade de aprendizagem de conteúdos específicos, e pode resultar na frustração do estudante e em evasão escolar.

Do ponto de vista social, as dificuldades na leitura fazem com que essa parcela da sociedade se limite a poucas fontes de informação, tornando-se pouco crítica e passível de manipulação. Em geral sua opinião é formada não a partir do estudo e comparação de fontes variadas de informação ou das interpretações científicas elaboradas sobre os fenômenos, mas a partir dos discursos hegemônicos veiculados pelos meios de comunicação. No Brasil, esse é um problema não só de aprendizagem, mas um problema político que revela as limitações do sistema de educação básica, a negligência histórica para com a formação de leitores e a insuficiência das políticas públicas. Embora o analfabetismo esteja diminuindo, no Brasil 6,8\% da população ainda é analfabeta (PNUD, 2018), cerca de 11 milhões de pessoas.

Com a pesquisa "Formação de leitores em Porto Velho/RO: uma análise das políticas públicas de formação de leitores no Campus Calama do Instituto Federal de Rondônia" buscamos mapear as dificuldades de leitura apresentadas pelos estudantes do curso Técnico de Eletrotécnica Integrado ao Ensino Médio e comparar as ações desenvolvidas nessa unidade educacional com as políticas e diretrizes nacionais.

A pesquisa teve como objetivo geral discutir as políticas públicas nacionais de formação de leitores verificando sua replicação na unidade de ensino selecionada. Dentre seus objetivos específicos previu-se: (1) elaborar um diagnóstico das principais dificuldades dos discentes no desenvolvimento da prática da leitura na unidade do IFRO selecionada, assim como (2) levantar dados sobre o acervo bibliográfico do Campus e as condições de acesso para ele.

As hipóteses que nortearam a pesquisa foram (1) a de que o analfabetismo funcional restringe o desenvolvimento profissional, (2) a de que leitura de textos didáticos é essencial para a formação das pessoas, mas não forma leitores e (3) que o incentivo à leitura de textos literários favorece o desempenho do estudante na produção de textos. 
Os resultados aqui apresentados, embora modestos, lançam luzes favoráveis à compreensão dos desafios da formação de leitores no Campus Porto Velho Calama, das práticas de leitura dos alunos do curso de Eletrotécnica, bem como dimensiona a replicação das políticas públicas nacionais de incentivo à leitura efetivadas nesta unidade de ensino.

\section{PERCURSO METODOLÓGICO}

Esta pesquisa foi desenvolvida em abordagem qualitativa, inserindo-se no campo da pesquisa educacional. Envolveu procedimentos da pesquisa de campo e da pesquisa documental e seu recorte empírico foi o Campus Porto Velho Calama do Instituto Federal de Educação, Ciência e Tecnologia de Rondônia.

Quanto à natureza configura-se como Pesquisa Básica e quanto aos objetivos, como Pesquisa Explicativa. No que diz respeito aos procedimentos utilizados, caracteriza-se como Pesquisa Educacional (GIL, 2008; FAZENDA, 2000). Enquanto pesquisa básica, seu propósito foi produzir conhecimento útil para o avanço da ciência, sem previsão, contudo, de aplicação prática para resolução de problemas específicos. Seus objetivos configuraram-se como de tipo explicativo tendo em vista extrapolarem o campo da descrição, perfazendo interpretações que almejam a explicação do fenômeno estudado.

A coleta de dados foi procedida mediante aplicação de questionários e pesquisa documental. Foram aplicados 130 questionários a estudantes das turmas do $1^{\circ}$ ano, $2^{\circ}$ ano, $3^{\circ}$ ano e $4^{\circ}$ ano de Eletrotécnica do Campus Porto Velho Calma, dos turnos matutino e vespertino, dos quais 111 questionários foram validados. O questionário aplicado aos estudantes teve perfil misto, com questões abertas e fechadas. Destas, 6 questões foram objetivas e 4 subjetivas, oportunizando espaço para os estudantes se expressarem acerca de suas experiências como leitores.

A pesquisa documental foi realizada em bancos de dados públicos, disponíveis na rede mundial de computadores, como o site do IBGE, do INEP e em legislação nacional que regulamenta políticas públicas educacionais. Esses dados foram fichados, 
assim como obras bibliográficas concernentes ao estudo. Já os dados resultantes dos questionários aplicados foram tabulados no software Excel, versão 2010.

As análises foram realizadas com base em literatura especializada sobre o assunto e evidenciaram um quadro educacional complexo, desafiador, mas também promissor em vários aspectos.

\section{RESULTADOS E DISCUSSÃO}

Em 6 de dezembro de 2016 a Folha Carta Educação, da Revista Carta Capital apresentou a matéria intitulada "Brasil mantém últimas colocações no Pisa" (PAIVA, 2016). O texto se referia ao baixo desempenho do Brasil no PISA, exame trienal coordenado pela Organização para a Cooperação e Desenvolvimento Econômico (OCDE) com o intuito de aferir a qualidade, equidade e eficiência dos sistemas escolares. O referido exame testou 540 mil estudantes de 15 anos de idade, de 72 países. Nas três áreas avaliadas: ciências, leitura e matemática, os estudantes brasileiros tiveram desempenho abaixo da média da OCDE, colocando o Brasil na $63^{\mathrm{a}}$ posição em ciências, na $59^{\mathrm{a}}$ em leitura e na $66^{\mathrm{a}}$ colocação em matemática. Paiva (op cit.) esclarece que os alunos brasileiros obtiveram 401 pontos contra 493 pontos da média da OCDE, em leitura, 407 pontos ante 493, em ciências e 377 pontos contra 490, em matemática. Estamos, portanto, distantes de alcançar a média, que significa conhecimento e competência mediana para a resolução dos problemas propostos em relação às áreas avaliadas.

Também no ENEM - Exame Nacional do Ensino Médio há estudantes que zeram a prova, inclusive a de redação, por fuga ao tema ou dificuldade em redigir três parágrafos minimamente lógicos, mesmo com o subsídio dos textos motivadores. De acordo com o site de notícias Portal MEC, os resultados deste exame estão estagnados desde o ano de 2008 e o desempenho dos estudantes na prova de redação continua sendo desafiador:

Redação - Na prova de redação, a maioria dos participantes (1.987.251) conseguiu notas entre 501 e 600. Apenas 77 
ISSN: $2594-4827$

conseguiram nota mil. A nota zero ou a anulação da prova foi para 291.806 estudantes.

Das anuladas, a maioria (206.127) resultou de não comparecimento ao segundo dia ou apresentação da redação em branco. Das redações que tiraram zero, os principais motivos foram fuga ao tema (46.874), parte desconectada (13.276), cópia de texto motivador (8.325), texto insuficiente (7.348) e não atendimento ao tipo textual (3.615). Por ferirem os direitos humanos, foram anuladas 4.798 (PORTAL MEC, 2016, s/p)

O baixo desempenho dos estudantes brasileiros em exames como os citados não é recente, configurando-se como um problema complexo e de longa duração. Para o enfrentamento do problema faz-se necessárias ações em diversas frentes, que englobam desde a melhoria da formação dos professores, a ampliação de recursos para a educação pública, o cumprimento da legislação concernente ao tema e até a construção de uma nova cultura, mais sensível à importância dos estudos.

Fazemos parte de uma sociedade que por três séculos viveu sob domínio colonial, forçada ao trabalho escravo ou semiescravo, sem condições e sem liberdade para pensar e produzir conhecimento de modo autônomo. Quando alcançamos a independência jurídica, nos submetemos ao jugo do capitalismo inglês e, posteriormente, transnacional, nos posicionando, na divisão internacional do trabalho, como mão de obra pouco especializada e fornecedora de commodities. Enquanto mão de obra pouco valorizada, não nos foi requerido estudar e aprofundar conhecimentos, discutir ideias, produzir obra de valor intelectual, o que explica o descaso social de nossa sociedade para com a cultura acadêmica. Conforme explica Lois (2010, p.38), "a leitura faz parte de um todo educacional que, desde a colonização, deixou uma marca na formação cultural do cidadão brasileiro: a da precariedade e do improviso".

Por outro lado, a concentração de renda que marca a sociedade brasileira interditou o acesso de ampla camada da população aos bens culturais, como livros e bibliotecas, e a intervenção insuficiente do Estado na disponibilização desses bens de forma pública gratuita contribuiu ainda mais para a exclusão dos mais pobres, perpetuando um cenário de violência simbólica e econômica.

Diante do exposto, cumpre efetuar a descolonização cultural, a fim de se traçar projetos mais autônomos para o desenvolvimento nacional. A formação de leitores é 
atividade imprescindível para isso, porque "As experiências através da leitura, além de facilitar o posicionamento do ser do homem numa condição temporal e espacial usufruindo dos bens culturais escritos, também são as grandes fontes de energia que impulsionam a descoberta e difusão do conhecimento". (LIRA, 2010, p. 124).

A luta pós-colonial demanda um tipo de educação diferenciada, que alfabetize não só para a decodificação dos signos e fonemas, mas para a decifração do mundo.

Em conformidade com a epistemologia freireana entendemos que a “alfabetização não é um jogo de palavras, é a consciência reflexiva da cultura, a reconstrução crítica do mundo, a abertura de novos caminhos, o projeto histórico de um mundo comum, a bravura de dizer sua palavra (FREIRE, 1987, p. 7), e nessa concepção pedagógica, a "palavra" significa "palavra e ação". "É significação produzida pela práxis, palavra cuja discursividade flui da historicidade - palavra e dinâmica, não categoria inerte, exânime, palavra que diz e transforma o mundo" (FREIRE, 1987, p. 8). Para tanto, é indispensável o compromisso governamental e social com a educação, bem como a qualificação profissional dos educadores, para que possam compreender não só os fundamentos técnicos e didáticos de seu ofício, mas, sobretudo, sua responsabilidade histórica.

Esse entrelaçamento de sujeitos efetivamente comprometidos com a educação é uma das maiores demandas de nosso tempo. Se um elo dessa corrente afrouxa ou se rompe, os esforços empreendidos tendem a se perder no caminho.

Com o intuito de melhorar os indicadores educacionais e obter seus benefícios conexos, o Estado brasileiro tem procurado implementar políticas públicas de formação de leitores, dentre as quais se pode citar o PNBE - Programa Nacional Biblioteca na Escola, o Programa Nacional do Livro Didático e o documento norteador denominado "Por uma política de formação de leitores". Antes de discorrer sobre estes programas específicos, destacamos que o Ministério da Educação (MEC) é o principal indutor de políticas públicas de formação de leitores no Brasil, e a maior parte de suas ações são conduzidas pela SEB - Secretaria de Educação Básica, tendo em vista que os processos iniciais de formação de leitores se dá nas séries iniciais da vida escolar e no Ensino 
Fundamental, fase da vida em que as crianças passam pelo processo de aquisição da escrita e da leitura.

\section{Por uma política pública de formação de leitores}

Em 2006 o Ministério da Educação publicou o documento intitulado "Por uma política de formação de leitores" (BERENBLUM, 2006). Este documento é basilar das políticas públicas direcionadas ao setor e teve como objetivo instigar o debate acercado papel da escola no desenvolvimento das competências relativas à leitura dos estudantes em processo de formação escolar.

O documento Políticas Públicas de Formação de Leitores foi enviado às escolas e às secretarias estaduais de educação, para conhecimento dos gestores, professores e profissionais responsáveis pela biblioteca. $\mathrm{O}$ documento foi publicado em forma de livro e junto com ele foram enviados outros dois volumes: "Biblioteca na Escola", que apresenta reflexões pertinentes e atualizadas sobre a leitura na escola e sugere atividades pedagógicas para serem desenvolvidas pelos docentes, com vistas a estimular a leitura e otimizar o uso dos acervos e "Dicionários em Sala de Aula", que apresenta orientações para o uso de dicionários e oferece diversas proposta lexicográficos para trabalho em sala de aula, bem como disponibiliza dicionários para o uso escolar.

Concentraremos nossa análise no volume 1, que é o documento de diretrizes da Política Nacional de Formação de Leitores. O referido documento está organizado em cinco partes, antecedidas de uma Apresentação e de uma Introdução. A primeira parte: Breve histórico das ações do Ministério da Educação na área da leitura, do livro e da biblioteca escolar apresenta considerações sobre as ações do Ministério da Educação em relação ao incentivo à leitura. Depreendeu-se do texto que, ao longo de várias décadas a principal ação do referido ministério se concentrou na distribuição de livros didáticos. A partir de 1997, com a criação do Programa Nacional Biblioteca da Escola houve diversificação do tipo de obras disponibilizadas para as bibliotecas escolares (já não se restringiam aos livros didáticos) e em 2000 foi conduzida uma experiência piloto de distribuição de obras voltadas para a formação docente de profissionais atuantes no primeiro ciclo do Ensino Fundamental ( $1^{\mathrm{a}}$ a $4^{\mathrm{a}}$ série). 
No triênio seguinte (2001 a 2003) uma nova experiência foi oportunizada pelo MEC, mediante o Programa Nacional Biblioteca da Escola - Literatura em Minha Casa e Palavra da Gente - que distribuiu coleções literárias para uso pessoal de estudantes de $4^{\mathrm{a}}$ a $8^{\mathrm{a}}$ série, que puderam levar esses livros para casa e apreciá-los juntamente com seus familiares. O compartilhamento de histórias entre pais e filhos e entre irmão e primos foi um elemento positivo desta experiência. Em muitas famílias, esta foi a primeira vez que se teve acesso a livros e à leitura em casa. Em função de críticas realizadas a esse programa, em 2005 o MEC o suspendeu e retomou a distribuição de acervos para uso coletivo, nas bibliotecas escolares.

A principal crítica tecida em relação ao "Literatura em Minha Casa" foi o fato de ter sido realizado em detrimento da transferência de livros aos acervos públicos. Assim, ao passo em que se oportunizou o acesso à literatura no âmbito doméstico e familiar, se negligenciou as bibliotecas públicas escolares, que ficaram estagnadas. O ideal teria sido a manutenção das duas ações pelo Estado: o incentivo à leitura nas bibliotecas públicas escolares, com a ampliação e renovação de seu acervo, o incentivo à leitura nos espaços domésticos, com doação de livros para os estudantes compartilharem com seus familiares.

A seção dois do documento em análise, denominada "Indicadores e mitos sobre a leitura na sociedade e na escola brasileira" retoma dados da pesquisa Leitura e Leitores no Brasil, realizada pela ALB - Associação de Leitura do Brasil, entidade privada composta por fabricantes de papel e donos de editoras e jornais no país. A pesquisa criticou o fato de se ter no Brasil uma visão supostamente romântica da leitura e da literatura, que desprezaria bestsellers, livros religiosos e de auto-ajuda. Segundo a pesquisa, os brasileiros lêem sim, em materiais e suportes variados, no entanto, lêem menos do que cidadãos de outros países, e relacionam-se a isso a baixa escolaridade, a baixa qualidade da educação pública ofertada e as condições de acesso aos livros. Um dos pontos mais surpreendentes da seção dois é o fato de o MEC reconhecer que os professores padecem de formação acadêmica precária, de limitada competência leitora e recebem baixos salários. 
A crítica que se estabelece acerca dessa seção do documento base das políticas públicas de formação de leitores no Brasil consiste em ele não apresentar propostas de superação para os problemas constatados. Dizer que é preciso quebrar preconceitos em relação à leitura e considerar os diversos textos em circulação (jornais, blogs, literatura religiosa e de auto-ajuda) é importante, no entanto, não soluciona o problema de que muitos brasileiros não conseguem compreender textos mais sofisticados, sejam as obras literárias clássicas da literatura nacional e mundial, sejam livros e manuais técnicos ou bulas de remédios. É preciso incentivar a leitura de obras em mídias e formatos variados. Para isso é preciso enfrentar na raiz o problema da baixa escolaridade, das dificuldades de acesso e permanência nas escolas e universidade, e das falhas na formação de professores. Em relação a esse aspecto é preciso considerar a falta de formação continuada no trabalho, a sobrecarga de trabalho, que muitas vezes impedem os docentes de desfrutar da leitura e se aperfeiçoar e os baixos salários, que forçam os professores a terem até três empregos para suprir as necessidades econômicas familiares.

A terceira seção "A pesquisa avaliativa realizada pelo Ministério da Educação" discute os resultados da pesquisa realizada em 2005, pela ALPAC - Associação LatinoAmericana de Pesquisa e Ação Cultural. A pesquisa teve recorte bastante limitado, abrangendo apenas 196 escolas de Ensino Fundamental, em 19 municípios de oito estados. Revelou que o livro ainda é tratado como objeto de tombamento, perene, que impossibilita uma relação mais próxima e intimista do leitor com ele. Com relação às bibliotecas, a pesquisa sugeriu que na maioria das escolas investigadas as preocupações com a biblioteca se referem mais à sua infraestrutura física do que com a função e os usos sociais que possibilita. Destacou ainda que muitas escolas não possuem biblioteca, mas contam apenas com salas de leitura, "cantinhos" e outros espaços adaptados, que não atendem de modo pleno a função de biblioteca. Além do que, notou-se dificuldade em articular os usos da biblioteca com projetos de leitura: os que usam as salas de leitura não incentivam a utilização da biblioteca, e vice-versa, carência de profissionais formados em biblioteconomia para coordenar projetos educativos específicos e promover a organização eficiente dos acervos. 
No que concerne às práticas pedagógicas, a pesquisa constatou que faltam orientações aos professores quanto ao uso dos acervos literários do PNBE, evidenciando confusão em relação ao livro didático, livro paradidático, obra de referência e obra literária, propriamente dita. $\mathrm{O}$ tratamento dado às obras literárias tem priorizado a compreensão do gênero literário em moldes acadêmicos, quando se poderia valorizar também a fruição do lúdico, da linguagem e a análise discursiva. Para estudantes do primeiro ciclo do Ensino Fundamental, não seria impróprio estimular o lúdico, a leitura por prazer (descompromissada de cobranças acadêmicas), a leitura de obras ilustradas e histórias em quadrinhos, apresentando às crianças um caminho de aventura por meio da literatura, que as prepararia para, no futuro, fazerem interpretações mais rigorosas sobre os gêneros, estilos e escolas literárias às quais seus autores se vinculam.

As práticas pedagógicas analisadas transparecem certo preconceito em relação às novas gerações de escritores e às novas estéticas criativas, resta saber, contudo, se as escolas de fato dispõem dessas obras modernas, se os professores estão capacitados para trabalhar com elas e se há afinidade entre elas e o currículo formal proposto pela escola, para que o professor não se sinta desviante das práticas legitimadas.

A parte quatro, "Por uma política de formação de leitores" é a que expressa de modo preciso as concepções e diretrizes que guiam o Estado brasileiro em relação a esta temática. Expressa o entendimento de que a leitura, enquanto prática sociocultural deve compor um conjunto amplo de ações, que não se limite ao espaço escolar. Este, todavia, deve continuar sendo privilegiado, por se tratar de espaço democrático (acessível a todos, ao menos do ponto de vista legal) e que tem função formativa. Sugere o compartilhamento de responsabilidade do Estado com a sociedade, no que diz respeito ao estímulo à leitura, por meio de redes de troca de conhecimento que tomem a leitura como ponto de estímulo aos debates. Criar locais de encontro para a leitura e o debate são iniciativas que podem favorecer a cultura escrita, bem como a democracia e participação social.

Esta seção discute ainda as duas dimensões distintas da leitura, a saber: a fruitiva e a informativa, apresentando-as como "dimensões complementares e decisivas para a formação do pensamento autônomo" (BERENBLUM, 2006, p. 23). Defende que a 
leitura pode e deve ser feita em suportes variados e que essa variedade de suportes favorece a compreensão das linguagens e códigos, e que os alunos devem ser respeitados em suas escolhas referentes às formas de manifestação artística, sem que lhes seja imposto as que são consideradas de maior prestígio. Às escolas caberia mostrar aos estudantes a diversidade literária, facultando-lhes a escolha do que desejam apreciar, e disponibilizar textos informativos variados, sobretudo os de utilidade pública.

Outro aspecto abordado na seção 4 é o da escrita, que não deve ser vista como inferior à leitura, mas trabalhada de modo conjunto, e não só nos ambientes escolares, mas fora deles também. Nos ambientes escolares, o documento recomenda o incentivo à produção textual, para que os estudantes não sejam só consumidores de textos escritos, mas também autores, produtores de cultura e se percebam como tal. Critica o estabelecimento de modelos prontos a serem seguidos, que desestimulam a criatividade do educando, bem como a exigência de cópias sem reflexão, que tornam a atividade sem sentido e fazem o estudante percebê-las como punição.

O capítulo cinco: "Ações para viabilizar uma política de formação de leitores" apresenta as seguintes ações como propostas para a formação de leitores: (1) qualificação de recursos humanos, incluindo a formação continuada de profissionais da escola responsáveis pela área da leitura, (2) distribuição de periódicos nas escolas, (3) ampliação das oportunidades de acesso de alunos, professores e comunidade a diferentes materiais de leitura, (4) Ampliação e implantação de bibliotecas escolares e dotação de acervos (PNBE).

Considera-se positivo o desenvolvimento de política pública de formação de leitores que contemple a dimensão da formação continuada, e inclua não só os professores, como os bibliotecários, coordenadores de salas de leitura e profissionais em readaptação. A formação continuada poderá favorecer a formação de leitores plenos, e não apenas isso, a formação também de redatores, que registrarão suas práticas pedagógicas e as reflexões em torno das experiências construídas no bojo dessa política pública. 
As políticas públicas de formação de leitores expressam o compromisso do MEC em promover educação para construção das habilidades de leitura e escrita dos estudantes de Ensino Fundamental e EJA. Infelizmente, o documento analisado não contempla estudantes de Ensino Médio, e com exceção da distribuição de livros didáticos não se localizou nenhuma outra política pública de fomento à leitura e à formação de leitores direcionada a esse público.

Outra crítica que se tece ao documento diz respeito à não pactuação de ações específicas para a formação continuada de professores. A esse respeito, Junqueira (2004, p. 57) esclarece:

É importante que se tenha claro que somente aquele que lê e que ama os livros é capaz de formar outros leitores. Nesse sentido se queremos formar leitores em nosso país, é necessário que se invista na formação inicial e continuada dos professores, com a destinação de recursos, tempo e espaço com o objetivo de criar uma comunidade de leitores.

Desse modo, é preciso mais que o fornecimento de livros, revistas e catálogos aos professores. É preciso enfrentar o problema das condições de trabalho e as perdas salariais acumuladas ao longo do tempo, para que livres das pressões econômicas possam voltar a ler e estudar.

\section{O Programa Nacional Biblioteca da Escola}

O Programa Nacional Biblioteca da Escola -PNBE foi criado pela Portaria $\mathrm{n}^{\circ}$ 584,28 de abril de 1997 e tem como objetivos: (1) manter os acervos das bibliotecas públicas com obras de literatura brasileira, textos de formação histórica, econômica e cultural, e de dicionários, atlas, enciclopédias e outras matérias de apoio, além de obras de referência. (2) produção e difusão de materiais destinados a apoiar projetos de capacitação e atualização do professor que atua no ensino fundamental. (3) apoio e difusão de programas destinados a incentivar o hábito da leitura (4) produção e difusão de materiais de audiovisuais e de caráter educacional e científico. A partir de então outras portarias foram criadas aprimorando o programa em curso. 
Entre as prioridades do PNBE estão a difusão e apoio a programas destinados a incentivar o hábito da leitura, uma vez que se esta for incorporada às práticas sociais, favorecerá o desenvolvimento da cidadania, oportunizando o incremento do repertório crítico (LOIS, 2010).

\section{Conforme o Ministério da Educação:}

Uma ação pública de incentivo à leitura, como parte da política educacional, tem por princípio proporcionar melhores condições de inserção dos alunos das escolas públicas na cultura letrada, no momento de sua escolarização. Constitui, ainda, no contexto da sociedade brasileira, uma forma de reverter uma tendência histórica de restrição do acesso aos livros e à leitura, como bem cultural privilegiado, a limitadas parcelas da população. A instituição, pelo Ministério da Educação, de uma política de formação de leitores, é, portanto, condição básica para que o poder público possa atuar sobre a democratização das fontes de informação, sobre o fomento à leitura e à formação de alunos e professores leitores (MEC, 2008, p. 8)

O PNBE é desenvolvido por meio de três ações principais: (1) PNBE Literário, que avalia e distribui as obras literárias, cujos acervos literários são compostos por textos em prosa (novelas, contos, crônica, memórias, biografias e teatro), em verso (poemas, cantigas, parlendas, adivinhas), livros de imagens e livros de história em quadrinhos; (2) PNBE Periódicos, que avalia e distribui periódicos de conteúdo didático e metodológico para as escolas da Educação Infantil, Ensino Fundamental e Médio e o (3)PNBE do Professor, que tem por fito apoiar a prática pedagógica dos professores da educação básica e também da Educação de Jovens e Adultos, mediante disponibilização de obras de cunho teórico e metodológico.

Este Programa tem realizado avaliação periódica das obras adotadas para distribuição, com vistas a fornecer a estudantes e docentes material de leitura variado e de qualidade, capaz de incentivar tanto a leitura literária, como fonte de fruição e 
reelaboração da realidade, quanto a leitura como instrumento de ampliação de conhecimentos, (PORTAL MEC, 2017).

Ainda segundo o site de notícias (PORTAL MEC, 2017), para receberem os acervos as escolas públicas precisam estar cadastradas no censo escolar realizado anualmente pelo Instituto Nacional de Estudos e Pesquisas Educacionais Anísio Teixeira (INEP). A distribuição dos livros é feita diretamente das editoras para as prefeituras ou secretarias municipais de educação. Dependendo do tipo de acervo, das editoras a um centro de mixagem, para formação das coleções e posterior envio às escolas.

O financiamento desse Programa é feito com recursos consignados no orçamento do Fundo Nacional de Desenvolvimento da Educação (FNDE). Sua execução é dirigida pelo FNDE e conta com a participação da SEB - Secretaria de Educação Básica, da SEESP - Secretaria de Educação Especial da SECAD - Secretaria de Educação Continuada, Alfabetização e Diversidade, por meio de procedimentos específicos definidos na Resolução ${ }^{\circ} 7$, de 20 de março de 2009

Consideramos esse programa de alta relevância para o incentivo à leitura e a democratização do acesso a livros e bibliotecas. O acervo disponibilizado compreende os clássicos da Literatura Brasileira e da Literatura Infanto-juvenil, incluindo fábulas e lendas do folclore universal.

A crítica que tecemos a seu respeito centra-se em três elementos: a limitação de sua área de abrangência, a limitação à ação distributiva e a falta de integração com a política federal de bibliotecas do Ministério da Cultura. O programa se restringiu, em seus primeiros anos, ao atendimento de estudantes de Nível Fundamental de escolas públicas, deixando os estudantes de Ensino Infantil e de Ensino Médio sem cobertura específica.

A partir de 2008 o programa ampliou seu escopo de atendimento com acervos de obras literárias destinada ao Ensino Médio, porém esses acervos ainda são escassos e não atendem a toda a demanda desse segmento. 
Por outro lado, critica-se o fato de se balizar à função distributiva de livros, quando poderia diversificar as ações, fomentando oficinas, seminários, cursos de redação e prêmios, tanto para estudantes quanto para professores. Falta integração com outras políticas públicas, sobretudo com as do Ministério da Cultura. Além disso, o programa carecia, até 2008 , de uma política de avaliação de resultados e mensuração de impactos, mas essa lacuna tem sido superada progressivamente.

Elisa Campos Machado (2010) aponta ainda para a forma como as bibliotecas públicas são representadas no imaginário social brasileiro. Para ela,

Hoje vivendo na chamada sociedade da informação e do
conhecimento, e com as novas tecnologias a nosso favor, a biblioteca
pública, àquela criada e mantida pelo Estado, deveria ser o ponto de
apoio local para a sociedade ter acesso à informação e à leitura. No
entanto, no Brasil, essas bibliotecas, de modo geral, ainda são
entendidas pela população como um espaço unicamente físico, de
organização de documentos no suporte papel e que têm como
atividade principal o atendimento às pesquisas escolares. O discurso
político sempre defendeu e ressaltou a importância das bibliotecas
públicas, mas na prática pouco foi feito para apoiar efetivamente estas
instituições.

Da mesma forma, as bibliotecas escolares precisam ser pensadas como espaços dinâmicos, que integrem livros nos mais diversos formatos, favorecendo o acesso ao conhecimento, mas a política pública aqui em análise ainda se restringe à distribuição de acervos em papel, sem prever investimentos em tecnologias para registro e catalogação das obras, para acesso do leitor a mídias variadas e sem definir ações específicas para formação de profissionais para atuação em seu espaço. Sabe-se que em muitas bibliotecas escolares o profissional que presta atendimento aos leitores e organiza o acervo é um servidor sem formação específica na área, em geral debilitado e em processo de readaptação, sendo proveniente de outro setor. 
São muitos os desafios que ainda afetam a biblioteca escolar, mas sua existência é positiva e deve continuar. Muitos leitores e profissionais qualificados começaram a ler por intermédio delas, fruindo de seu acervo, por mais modesto que se apresente. $\mathrm{O}$ desafio contemporâneo é mantê-lo em funcionamento, dada a iminência de congelamento de recursos públicos para a educação e a concepção neoliberal que se anuncia na política brasileira.

\section{O Programa Nacional do Livro e do Material Didático}

O programa Nacional do Livro Didático é um dos mais antigos programas do PNDE do Governo Federal e está vinculada às políticas públicas de formação de leitores. Foi instituído em 1929 e desde então vem se desenvolvendo, ora com avanços, ora com recuos e interrupções. Em 2017 houve proposta de alteração do Programa por meio do Decreto 9.098, de julho de 2017, decreto este que foi publicado em 2 de janeiro de 2018 e que na sequência foi suspenso em razão de críticas apresentada por especialistas e pela sociedade em geral. Percebe-se desse modo que mesmo o Programa possuindo quase um século de história não está isento de jogos e interesse políticos e econômicos.

Atualmente, o Programa Nacional do Livro Didático é executado pelo FNDE Fundo Nacional de Desenvolvimento da Educação, conforme estabelecido na Resolução 42, de 28 de agosto de 2012, do conselho deliberativo do FNDE (FNDE, 2012). O Art. $8^{\circ}$ da referida Resolução estabeleceu que a execução do Programa ficará a cargo do FNDE e contará com a participação da SEB, das secretarias de educação dos estados, dos municípios e do Distrito Federal, das escolas participantes e dos professores, por meio de procedimentos específicos e em regime de mútua cooperação, de acordo com as competências de cada um. O financiamento é feito por meio de recursos provenientes de dotações consignadas no orçamento do Ministério da Educação

De acordo com o FNDE, o Programa Nacional do Livro Didático tem como objetivo prover as escolas públicas do Ensino Fundamental e Médio com livros didáticos, acervos literários, obras complementares e dicionários. O órgão informa ainda que oPNLD é executado em ciclos trienais alternados, de modo que a cada ano o FNDE adquire e distribui livros para todos os alunos de determinada etapa de ensino e repõe e 
complementa os livros reutilizáveis para outras etapas. O programa considera reutilizáveis os livros didáticos de Matemática, Língua Portuguesa, História, Geografia, Ciências, Física, Química e Biologia e considera consumíveis os de Alfabetização Matemática, Letramento e Alfabetização, Inglês, Espanhol, Filosofia e Sociologia (FNDE, 2017).

Esse Programa está estruturado em dois eixos principais: (1) Qualificação dos recursos humanos e (2) Ampliação do acesso a materiais de leitura diversificados. Esses eixos encontram-se detalhados no documento "Por uma Política de Formação de Leitores" (MEC, 2008).

O Programa se subdivide em quatro classes, que visam a atender populações específicas: PNLD EJA, para estudante da modalidade educacional Jovens e Adultos, PNLD Campo, para estudantes da zona rural de $1^{\circ}$ ao $5^{\circ}$ ano, PNLD Obras Complementares, que compõem acervos direcionados às turmas de alunos de $1^{\circ}$ ao $3^{\circ}$ ano do Ensino Fundamental, com o objetivo de desenvolver a aprendizagem no ciclo de alfabetização, PLD Alfabetização na Idade Certa e PNLD Dicionários. A alfabetização na idade certa se refere à meta nacional de alfabetizar todas as crianças até a terceira série do Ensino Fundamental e o PNLD Dicionários consiste na distribuição de dicionários de Língua Portuguesa a estudantes da educação básica da rede pública de ensino.

As críticas a esse Programa referem-se a três aspectos: (1) a limitação da oferta de livros em suporte papel, sem a alternativa da disponibilização em PDF, para download e consulta por dispositivos eletrônicos, como ocelular. (2) o fato de os livros de Língua Inglesa, Língua Espanhola, Sociologia e Filosofia serem tratados como "consumíveis", ou seja, terem apenas um ano de duração, quando poderiam ser aproveitados por um período maior e por um número maior de estudantes. (3) não oferta de livros didáticos específicos para estudantes indígenas, quilombolas e de populações tradicionais.

Quanto ao item dois acima elencado, entendemos que não há porque diferenciar os livros das disciplinas de Inglês, Espanhol, Sociologia e Filosofia dos de História, Geografia, Ciências e Matemática. Em um olhar mais abrangente sobre essa política 
pública, constata-se que livros didáticos informativos têm sido muito úteis na divulgação de informações, como um instrumento pedagógico importante, mas certamente, não formam leitores (JUNQUEIRA, 2004).

A leitura de textos didáticos é relevante para a formação acadêmica e técnica, mas não oportuniza o tipo de experiência própria da fruição de uma obra literária. Por conseguinte, o incentivo à leitura de textos ficcionais e poéticos favorece o desempenho do estudante na produção de textos, ao passo que a leitura e interpretação de manuais técnicos favorece o bom desempenho nas avaliações específicas dos componentes curriculares, bem como orienta para a atuação profissional.

\section{Experiências de leitura no IFRO - Campus Porto Velho Calama}

As experiências de leitura desenvolvidas no Campus Porto Velho Calama reproduzem, as experiências nacionais, fomentadas pelas políticas públicas direcionadas à área, mas também se expressam de forma própria, sobretudo nos grupos de pesquisa.

O Campus Porto Velho Calama participa do Programa Nacional do Livro Didático e do Programa Nacional Biblioteca na Escola, no entanto, o último repasse de livros desse programa para o Campus foi em 2013.

Em relação aos livros didáticos, foram distribuídos, em 2016 e 2017 mais de 10 mil livros didáticos, dos diversos componentes curriculares para os estudantes do Ensino Médio Integrado ao Técnico, conforme informou o bibliotecário Evandro Silva de Sousa. No que concerne ao acervo da biblioteca do Campus Calama, este é composto por 10.471 títulos, dos quais 740 são obras classificadas como de Linguística, Letras e Artes, 18 de Ciências Agrárias, 68 de Ciências Biológicas, 49 de Ciências da Saúde, 728 de Ciências Exatas e da Terra, 650 de Ciências Humanas, 369 de Ciências Sociais Aplicadas, 351 de Engenharias e 88 de Generalidades.

O sistema de gestão da biblioteca, o GNUTECA está integrado a outras bibliotecas do Estado, sendo facultado o empréstimo de obras disponíveis em bibliotecas de outros campi. O acesso ao acervo é franqueado a todos os que desejarem visitar a biblioteca, e ela funciona em três turnos ininterruptos, possuindo profissionais qualificados que também auxiliam nas pesquisas escolares e com sugestões de obras, 
quando indicado. A biblioteca, durante o trabalho de campo, foi frequentada por estudantes do Campus e estudantes da UNIR. Raramente notamos professores em seu espaço. Seu público é constituído, portanto, em sua maioria por estudantes de Ensino Médio e Ensino Superior.

O livro didático é o principal suporte de leitura desfrutado pelos estudantes dos cursos de Ensino Médio, sendo que paradidáticos e literários são lidos, sobretudo, quando exigidos pelos professores. Os livros didáticos são pouco lidos - de forma autônoma e voluntária - pelos estudantes entrevistados, sendo que as leituras são feitas, na maioria das vezes, em atendimento a pedido dos professores e quando é solicitado resolução de atividades dos capítulos ou quando a atividade vale ponto na nota. São raros os casos de estudantes que afirmaram terem lido os livros didáticos já no início do ano, para se inteirarem dos conhecimentos e facilitar a participação nas aulas. Lois critica esse comportamento: "O estudante se habituou à ideia de ler para realizar alguma tarefa e dever. Ora, se estabelecemos, na escola, a ideia de que ler é um ato que antecede uma obrigação, dificilmente o estudante despertará o prazer que poderia estar presente em relação com a literatura (LOIS, 2010, p. 80.

No que concerne aos empréstimos efetuados pelos estudantes em 2017 os livros de literatura, propriamente ditos, foram os mais procurados, mas ainda assim o número de empréstimo, segundo servidores da biblioteca é baixo.

O fato de livros didáticos e obras literárias serem pouco apreciadas entre os estudantes entrevistados, não quer dizer que leiam pouco - quer dizer que leem pouco aqueles tipos de textos. Esses estudantes interagem diariamente com grande quantidade de textos em blogs, sites e redes sociais, consumindo vorazmente as informações que lhes chegam à tela do celular, do tablet ou do computador. Em relação a isso, resta a necessidade de pesquisas específicas, a fim de se investigar os efeitos dessas leituras sobre a formação e posicionamento dos estudantes.

Apresentaremos a seguir dados específicos das respostas que obtivemos com as entrevistas realizadas. Entrevistamos 113 estudantes do curso de Eletrotécnica Integrado ao Ensino Médio, de todas as turmas e turnos, indistintamente. 
Do total de entrevistados 109 considerou que ler é importante e apenas 4 que a leitura é irrelevante para seus objetivos pessoais e profissionais. Ainda em relação à amostra 91 estudantes afirmaram que entendem o que lêem, 01 afirmou que não entende o que lê, 21 afirmou que somente às vezes entende o que lê. Depreendemos, desse modo, que 22 estudantes, declararam possuir dificuldade de leitura, o que corresponde a $19 \%$ da amostra.

É possível que haja, ainda, entre os que disseram não possuir dificuldades na leitura, pessoas com dificuldade nessa atividade intelectiva, mas que não quiseram declarar.

Ao questionarmos sobre a atitude quando iniciam a leitura de um livro, (se param no início, se vão até a metade, até o fim ou se apenas olham capa e figuras), as respostas foram assim entabuladas conforme a figura 1.

Ao questionarmos sobre como consideram o tempo dedicado à leitura, 36 dos estudantes avaliaram que o tempo que dedicam à leitura é suficiente, 74 responderam que é insuficiente e 03 não souberam informar.

O reconhecimento, por parte da maioria dos estudantes, de que o tempo que dedicam à leitura é insuficiente pode ser um ponto positivo para a mudança desse comportamento. Essa questão nos levou à seguinte, na qual investigamos os elementos que dificultam ou impedem a leitura.

A questão que indagou sobre o que dificulta o hábito de ler teve como resposta predominante "a falta de tempo", seguido de "lentidão na leitura". O fator preponderante indicado: falta de tempo, apontado por 72 dos estudantes entrevistados levaram-nos a refletir sobre as formas de ocupação do tempo dos adolescentes e jovens na atualidade. Entendemos que muitos vivem sobrecarregados de atividades, a maioria delas determinadas por seus progenitores ou responsáveis. A grande quantidade de atividades cotidianas que precisam ser conciliadas com as demandas da EPT faz com que se sintam, muitas vezes, em débito com uma ou outra ou que não consigam se dedicar de forma apropriada à leitura. 
Figura 1: Avanços na leitura de livro, Curso Técnico de Eletrotécnica, 2016

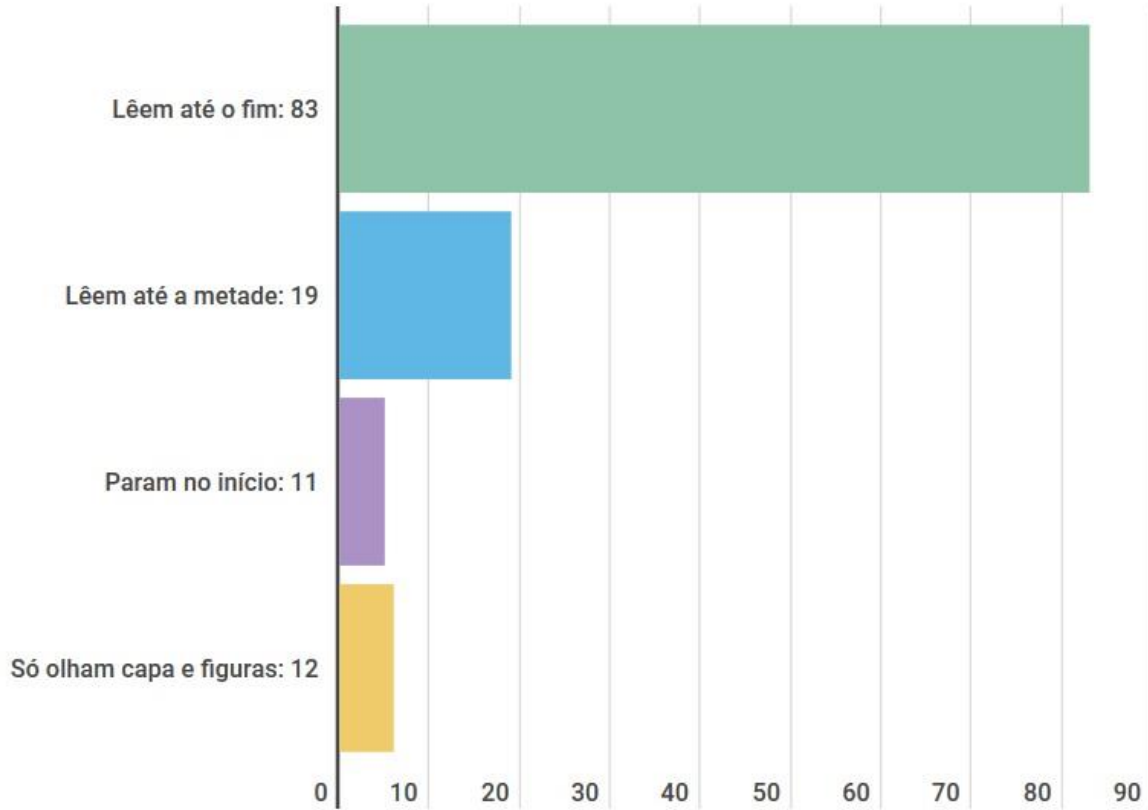

Fonte: Ruth Ferreira Bezerra, 2016.

O quadro 1 apresenta, de forma detalhada a periodicidade de leitura de determinados tipos textuais.

Quadro 1: periodicidade de leitura por tipo de texto, Curso de Eletrotécnica, 2016

\begin{tabular}{|c|c|c|c|c|c|}
\hline Tipo & Diariamente & Semanalmente & Mensalmente & $\begin{array}{c}\text { Quando é cobrado } \\
\text { na escola }\end{array}$ & Nunca \\
\hline $\begin{array}{c}\text { Literatura } \\
\text { clássica }\end{array}$ & 10 & 16 & 26 & 52 & 7 \\
\hline Jornal & 32 & 17 & 15 & 08 & 45 \\
\hline $\begin{array}{c}\text { Manuais e } \\
\text { livros } \\
\text { didáticos }\end{array}$ & 45 & 25 & 16 & 17 & 3 \\
\hline $\begin{array}{c}\text { Textos de } \\
\text { internet }\end{array}$ & 87 & 08 & 03 & 06 & 2 \\
\hline
\end{tabular}

Fonte: Ruth Ferreira Bezerra, 2016. 
Com base no quadro acima, fica evidente que os textos de internet são os mais lidos, seguidos pelos manuais e livros didáticos. Surpreendente é a quantidade de estudantes que "nunca lêem" e que fazem da leitura uma atividade meramente protocolar, realizada em atendimento às exigências acadêmicas. Esses provavelmente ainda não descobriram o prazer da leitura nem sua importância para a vida profissional e cidadã.

O gênero preferido dos estudantes, conforme informado na entrevista é o gênero literário, propriamente dito, nele estando incluso uma diversidade de temas e abordagens. Classificamos sob esse gênero uma diversidade de respostas que indicaram elementos como: "romance", "poesia", "ficção científica", "Machado de Assis" e "naturalismo", por ser inviável retornar a campo e aplicar novo instrumento, detalhando os elementos indicados. Alguns itens tiveram pouca preferência, como por exemplo: "carros e motos" (apenas dois estudantes manifestaram preferência por este assunto) e HQ - Histórias em Quadrinhos e Comédia, ambos preferidos por apenas três estudantes, mas optamos por mantê-los a título de informação acerca da diversidade de gostos e estilos.

Dentre as principais dificuldades relacionadas à leitura, constam: dificuldade de interpretação - que foi a principal dificuldade registrada pelos entrevistados, falta de tempo, já discutida anteriormente, falta de local adequado para a leitura e falta de motivação, seguidas do problema do analfabetismo funcional.De acordo com Fisher (2016, p. 11), a leitura é a "capacidade de extrair sentido de símbolos escritos ou impressos". Essa definição continuará, por certo, a se expandir no futuro porque, assim como qualquer outra aptidão, ela também é um indicador de avanço da própria humanidade".

Conforme Dahene (2007), a leitura decorre de um conjunto complexo de atividades neurais que envolve as vias visuais, motoras, auditivas e de formação de sentido. Essa atividade vital, não ocorre, contudo, apenas como processo fonológico, desenvolvido a partir de sinapses e conexões neurológicas, mas é também um processo cultural, que ocorre conforme as especificidades e condições materiais e educacionais disponíveis em cada sociedade. Nesse sentido, pode-se afirmar que as dificuldades de 
leitura apresentadas pelos estudantes entrevistados são predominantemente decorrentes de limitações das práticas culturais em que estão envolvidos.

De acordo com Kleiman (1996, p.10), "Ao lermos um texto, qualquer texto, colocamos em ação todo nosso sistema de valores, crenças e atitudes que refletem o grupo social em que se deu nossa alfabetização primária, isto é o grupo social em que fomos criados". Desse modo, é preciso ampliar os horizontes culturais dos estudantes, sem, contudo, desrespeitar os referentes de seu modo de vida e de sua identidade. É esse o papel da escola, no entanto, apesar de sua longa existência e trajetória, não há fórmula pronta para isso. Sem dúvidas, promover o acesso a livros, reduzir as desigualdades de acesso à informação, incentivar a leitura, promover o letramento e a alfabetização crítica são atividades importantes, que devem ser feitas incansavelmente pelos profissionais comprometidos com a educação. Porém, não se deve acreditar facilmente em estratégias e fórmulas prontas, que podem funcionar para um indivíduo, mas não para o outro, para um grupo de determinada condição social, mas não para outro.

Não podemos esquecer que a leitura é um ato complexo, de exposição e interconexão de ideias e sistemas de pensamento, de decodificação e construção de sentidos, de diálogos com outros textos e experiências vivenciadas. O leitor não consome passivamente um texto, ele se apropria dele, o interpreta, desliza nele suas fantasias, seus desejos, suas angústias, muitas vezes até deturpa seu sentido ou o extrapola.

Se o leitor lê pouco, conhece poucos textos, suas atividades de leituras ficam restritas pois "ler é relacionar textos, concretos ou potenciais, remetendo-os uns aos outros e construindo sentido nesse movimento" (LIRA, 2010, p. 14)

Há textos que amamos à primeira vista e há textos com os quais travamos longas batalhas. A situação não é diferente para os adolescentes que entrevistamos, assim, a leitura tem seu próprio processo e o aprender a ler e gostar de ler se desenvolvem em ritmos próprios. A leitura é um gesto íntimo, discreto, que transita de um sujeito a outro, de um suporte a outro, que não se ajusta bem a uma programação. Se tentarmos capturar os leitores com redes, é possível que levantem voo para outros prazeres. 
Embora devamos respeitar as temporalidades próprias de cada leitor, não podemos ser omissos em promover ações que auxiliem a superar as dificuldades encontradas. A superação dessas dificuldades é muitas vezes decisiva para a permanência do estudante na escola, para seu êxito profissional e sua inclusão social. Nesse sentido, oficinas específicas são relevantes, intervenções artísticas, saraus, projetos temáticos. Mas também é fundamental a atenção que o professor dispensa a seus alunos no cotidiano da sala de aula, o ato gentil de ler junto, explicar, de ensinar a pesquisar no dicionário e de apresentar os autores que constituem a base de sua formação. De acordo com Lois "Se houver um equilíbrio entre mediar, auxiliar e dar liberdades de escolhas ao estudante, desde cedo ele terá mais possibilidade de ver na leitura um forte referencial de diálogo consigo e com o mundo" (LOIS, 2010, p. 59).

A leitura é uma atividade indispensável para o desenvolvimento da capacidade de elaboração de crítica, de leitura da realidade social e a formação da consciência histórica. Isso porque "a consciência é gerada na prática social de que se participa" (FREIRE, 2011, p.79). Nas palavras de Lira: “A leitura é, fundamentalmente, um ato político" (LIRA, 2010, p. 112).

Por isso é pertinente desenvolver uma alfabetização crítica, que vai além do ensinar a decodificar as palavras grafadas em um texto. A alfabetização crítica é uma atividade essencial para o empoderamento individual e social. Segundo Paulo Freire e Macedo, ela é

Uma infinidade de formas discursivas e competências culturais que constroem e tornam disponíveis as diversas relações e experiências que existem entre os educandos e o mundo. Em sentido mais específico, a alfabetização crítica é tanto uma narrativa para a ação, quanto um referente para a crítica. Como narrativa para a ação, a alfabetização torna-se sinônimo de uma tentativa de resgatar a história, a experiência e a visão do discurso convencional e das relações sociais dominantes. Ela significa desenvolver as condições teóricas e práticas mediante as quais os seres humanos podem situarse e suas respectivas histórias e, ao fazê-lo, fazer-se presente como 
agentes na luta para expandir as possibilidades da vida e da liberdade humana (FREIRE; MACEDO, 2011, p. 49-50)

Trata-se, portanto, de uma atividade que transcende o objetivo de construir competências e habilidades acadêmicas, mas objetiva contribuir com o próprio desenvolvimento humano, ampliando suas possibilidades de ser e estar no mundo.

\section{CONSIDERAÇÕES FINAIS}

É consenso que o povo brasileiro lê pouco, comparado a outros países. No entanto, no Brasil não faltam políticas públicas de formação de leitores e de incentivo à leitura. Há programas de destaque, como o Programa Nacional do Livro Didático, que existe desde 1929 e o Programa Nacional Biblioteca na Escola. O volume de recursos investidos anualmente nesses programas é considerável. O MEC chegou a ser reconhecido como o principal comprador e distribuidor de livros do mundo. Todavia, as avaliações dessas políticas públicas têm indicado resultados abaixo do esperado. A sociedade continua lendo pouco, os estudantes continuam apresentando baixo desempenho em exames como o ENEM e o PISA e até mesmo há professores que leem pouco, seja por falta de tempo e de condições, seja por dificuldades em sua formação.

Entendemos que essas políticas públicas precisam ser ampliadas e que são necessárias duas coisas: maior envolvimento da sociedade no planejamento e controle, ou seja, participação social nas ações, e aperfeiçoamento do sistema de avaliação e controle dessas políticas públicas. É preciso assegurar, por exemplo, que os livros didáticos e acervos literários cheguem no prazo (antes do início do ano letivo) em todas as escolas, inclusive nas escolas localizadas nas regiões mais recônditas e de difícil acesso. É necessário monitoramento das instituições de ensino acerca do uso feito dos livros e recursos a ela direcionados, pois são bens públicos. Igualmente relevante é promover a integração das políticas de formação de leitores com outras políticas públicas correlatas. Por exemplo, integrar as bibliotecas escolares com as bibliotecas municipais, estaduais e federais possibilitando o intercâmbio de obras, a promoção de ações conjuntas e adesão a atas e licitações, desburocratizando o processo de aquisição de obras bibliográficas. 
Em relação à experiência local, investigada por meio desta pesquisa, pode-se afirmar que o Campus Porto Velho Calama reproduz, em sua escala, as políticas nacionais para formação de leitores e que as dificuldades de leitura expressas por seus estudantes (os estudantes entrevistados) são semelhantes às dificuldades vivenciadas por estudantes de outras regiões do país.

Foram entrevistados 113 estudantes do curso de Eletrotécnica integrado ao Ensino Médio, dos quais 109 considerou que ler é importante e 4 consideraram que a leitura é irrelevante para seus objetivos pessoais e profissionais. Do total de entrevistados 91 estudantes afirmaram que entendem o que lêem, 01 afirmou que não entende o que lê, 21 afirmou que nem sempre compreende o que lê. Indagados sobre o que dificulta a consolidação do hábito da leitura 77 entrevistados afirmou ser a "falta de tempo", 19 a "lentidão na leitura", 02 a "dificuldade de uso da biblioteca", e 20 atribuem a falta de hábito a "outros fatores", não detalhados no instrumento de coleta de dados.

Os textos de internet são os mais lidos pelos estudantes entrevistados, seguidos dos manuais e livros didáticos. Houve alunos que afirmaram "nunca ler" ou ler apenas para atendimento às exigências acadêmicas, o que indica que muitos estudantes ainda não descobriram o prazer da leitura e sua relevância para a vida

Dentre os gêneros que mais atraem os estudantes constam o gênero literário e o gênero textual de tipo notícia, no sentido de informações gerais e curiosidades. Notícias jornalísticas são pouco lidas.

A auto percepção dos estudantes acerca das dificuldades de leitura apontou, na maioria dos casos, para dois problemas: o da dificuldade de interpretação e falta de tempo. A dificuldade de interpretação resulta de problemas que em geral vêm desde as séries iniciais: alfabetização incompleta, pouco contato com os vários gêneros textuais, limitadas experiências literárias, que não dão base para a intertextualidade e o enfrentamento dos desafios impostos pelos textos. A falta de tempo também é um fator considerável. Cada vez mais os adolescentes de classe média se envolvem em atividades extraescolares, como judô, ballet, natação, piano, e cada vez mais cedo os adolescentes de condição social humilde precisam trabalhar ou estagiar para ajudar na 
complementação do orçamento doméstico. Há ainda o estágio profissional, realizado pelos estudantes das turmas de $3^{\circ}$ e $4^{\circ}$ ano, que exige muito de seu tempo.

Defendemos que é preciso um trabalho pedagógico minucioso para a avaliação das dificuldades de leitura e a proposição de ações que auxiliem o estudante a superar as dificuldades e assim, ter melhores condições para prosseguir na vida escolar. Entendemos, também que não há fórmulas prontas e que cada leitor construirá formas e experiências únicas de leitura.

É preciso reconhecer que os estudantes chegam à escola com múltiplas inscrições de sua cultura. Chegam com crenças e hábitos já consolidados. Devemos respeitar seus conhecimentos e vivências históricas, compreender que as temporalidades são diferentes, mas também ampliar seus horizontes. Nesse sentido, promover o acesso a livros e à leitura, reduzir as desigualdades de acesso à informação e aos bens culturais e promover a alfabetização crítica são atividades importantes, que devem ser feitas de modo comprometido.

Saber ler é importante não só para o êxito acadêmico, mas também para a apropriação do mundo. A leitura é uma atividade indispensável para o desenvolvimento da capacidade de elaboração de crítica, de leitura da realidade social e a formação da consciência histórica. Deve ser fomentada pelo Estado, por meio de políticas públicas, e deve ser estimulada no IFRO e em todas as escolas e bibliotecas.

AGRADECIMENTOS: Agradecemos ao Departamento de Pesquisa, Inovação e Pósgraduação do IFRO - Campus Porto Velho Calama, pelo apoio e orientações prestadas.

\section{REFERÊNCIAS}

BERENBLUM, A. Por uma política de formação de leitores. Brasília: Ministério da Educação, Secretaria de Educação Básica, 2006.

FAZENDA, I. Metodologia da Pesquisa Educacional. $6^{\text {a }}$ ed. São Paulo: Ed. Cortez, 2000 . 
FNDE. Fundo Nacional do Desenvolvimento da Educação. Resolução no 7, de 20 de março de 2009.

Fundo Nacional do Desenvolvimento da Educação. Resolução no 42, de 28 de agosto de 2012.

FREIRE, P. Pedagogia do Oprimido. Rio de Janeiro: Paz e Terra, 1987.

P.; MACEDO, D. Alfabetização: Leitura do Mundo, Leitura da Palavra. São

Paulo: Paz e Terra. 2011.

FISCHER, R. História da Leitura. São Paulo: UNESP. 2016.

GIL, A. C. Métodos e técnicas de pesquisa social. 6 ed. São Paulo: Atlas, 2008.

JUNQUEIRA, S. R. Caminhos para a formação do leitor. São Paulo: Ed. Difusão Cultural do livro, 2004.

KLEIMAN, A. Oficina de leitura: teoria e prática. Campinas: Ed. EDUNICAMP, 1996.

LIRA, B. C. Leitura e recontextualização: o discurso multicultural (Coleção Comunicar), São Paulo: Ed. Paulinas, 2010.

LOIS, L. Teoria e Prática da Formação do Leitor: Leitura e literatura na sala de aula. Porto Alegre: Ed. Artemed, 2010.

MACHADO, E. C. I Análise de políticas públicas para bibliotecas no Brasil. Revista. Ci. Inf. e Doc., Ribeirão Preto, v. 1, n.1, p. 94-111, 2010.

MEC. Ministério da Educação (Brasil). Portaria n. 584, de 28 de abril de 1997.

Programa Nacional Biblioteca da Escola (PNBE): leitura e bibliotecas nas escolas públicas brasileiras/ Secretaria de Educação Básica, Coordenação-Geral de Materiais Didáticos; elaboração Andréa Berenblum e Jane Paiva. -Brasília: Ministério da Educação, 2008.

PAIVA, T. Brasil mantém últimas colocações no PISA. (6 de dezembro de 2016). Folha Carta Educação - Revista Carta Capital. Disponível em: <

http://portal.mec.gov.br/busca-geral/309-programas-e-acoes-1921564125/programanacional-biblioteca-da-escola-1229869342/12368-programa-nacional-biblioteca-daescolahttp://www.cartaeducacao.com.br/reportagens/brasil-mantem-ultimas-colocacoesno-pisa/> Acesso em 14 jun. 2017.

PNAD. Pesquisa Nacional por Amostra de Domicílios Contínua Educação (Pnad Educação). IBGE: Rio de Janeiro, 2018. 
PORTAL MEC. Ministro apresenta resultados gerais do Enem 2016 e celebra êxito na realização do exame. Disponível em:

<http://portal.mec.gov.br/component/content/article?id=44111> Aceso em 14 jun. 2017.

PORTAL MEC. Programa Nacional Biblioteca na Escola. Disponível em:<http://portal.mec.gov.br/busca-geral/309-programas-e-acoes1921564125/programa-nacional-biblioteca-da-escola-1229869342/12368-programanacional-biblioteca-da-escola>2017 Acesso em 14 jun. 2017. 